\title{
Establishment and characterization of novel cell lines and xenografts from patients with gastrointestinal stromal tumors
}

\author{
KAZUMASA FUKUDA, YOSHIRO SAIKAWA, HIROYUKI SAKO, YUMI YOSHIMURA, TSUNEHIRO TAKAHASHI, \\ NORIHITO WADA, HIROHUMI KAWAKUBO, HIROYA TAKEUCHI, TAI OHMORI and YUKO KITAGAWA
}

Department of Surgery, School of Medicine, Keio University, Shinjuku-ku, Tokyo 160-8582, Japan

Received January 31, 2013; Accepted March 11, 2013

DOI: $10.3892 /$ or.2013.2425

\begin{abstract}
At present, no suitable GIST model exists for the analysis of drug resistance or metastasis using established human gastrointestinal stromal tumor (GIST) cell lines or xenografts even though the molecular mechanisms of drug resistance, progression and metastasis require clarification. The aim of this study was to establish and characterize human GIST cell lines and xenografts that can be used for evaluating drug resistance or various new molecularly targeted therapies. GIST tissues from patients were cultured and implanted under the skin of NOG (NOD/Shi-scid, IL-2Rrnu) mice. Two new cell lines (GK1C and GK3C) and three xenografts (GK1X, GK2X and GK3X) were generated from these clinical samples. The established GIST cell lines and xenografts were investigated for tumorigenesis and imatinib sensitivity. These cell lines and xenografts showed characteristic GIST morphology and exhibited KIT expression profiles similar to those of the patient samples. In addition, these GIST cell lines and xenografts were sensitive to imatinib. In conclusion, new human GIST cell lines and xenografts were established and maintained through repeated passages. These models will enable further study of combination therapies and the mechanisms of resistance, and allow testing of novel targeted monotherapies and combination therapies.
\end{abstract}

\section{Introduction}

Human gastrointestinal stromal tumors (GISTs), mesenchymal tumors of the gastrointestinal tract (1), originate from the neoplastic transformation of interstitial cells of Cajal (ICC),

Correspondence to: Dr Yoshiro Saikawa, Department of Surgery, School of Medicine, Keio University, 35 Shinanomachi, Shinjuku-ku, Tokyo 160-8582, Japan

E-mail: saiky@z8.keio.jp

Abbreviations: GIST, gastointestinal stromal tumor; NOG mice, NOD/Shi-scid, IL-2Rrnu mice; nude mice, BALB/cAJcl- $n u / n u$ mice; SCID mice, FOX CHASE SCID C.B-17/lcr-scid/scidJcl

Key words: GIST, imatinib, c-KIT, PDGFRA which frequently express mutations in the $c$-KIT gene and occasionally in PDGFRA (2). The resulting mutations of KIT and PDGFRA receptors result in constitutive activation of receptor kinase activity leading to downstream effectors that deregulate cell proliferation and survival, thereby accelerating malignant progression (3). Surgery is currently the first-line treatment for patients with primary resectable GISTs $(4,5)$. However, many patients develop recurrent or metastatic disease despite complete surgical resection (6) and since conventional chemotherapy or radiotherapy is usually ineffective (7). Thus, there are no ideal methods for treating such GISTs.

Imatinib mesylate (imatinib) is a tyrosine kinase (TK) inhibitor that targets BCR-ABL, PDGFR, KIT, DDR and CSFR, and has been used to treat certain patients with KIT-positive GISTs having constitutive activating mutations in KIT (8). Although more than $80 \%$ of inoperable KIT-positive GIST patients exhibit clinical benefits from imatinib, the tumors in most of these patients will eventually progress $(9,10)$. The activity of imatinib differs across various types of $c$-KIT and PDGFRA mutations, and secondary resistance in imatinibtreated patients often results from an emerging secondary mutation or amplification of $c-K I T$ or PDGFRA (11-13). Approximately $50 \%$ of GISTs with secondary resistance to imatinib is caused by mutations in $c$-KIT or PDGFRA (14-18). Several studies have reported that the RTK switch is associated with imatinib-resistance, but the other mechanisms of secondary resistance remain to be elucidated.

Although many GISTs are driven by activating KIT mutations, some tumors only express non-mutated KIT ( $c$-KIT mutation-negative GISTs) Although $c$-KIT mutation-positive GISTs show more frequent liver metastases and higher mortality than $c$-KIT mutation-negative GISTs $(19,20)$, the detailed mechanism of cell migration and metastasis in GIST has not been characterized. Molecular-based research on GIST has been hampered by a lack of the availability of suitable animal models with peritoneal dissemination or liver metastasis using human GIST tissues.

Our purpose in this study was to establish cell lines and xenografts models from clinical samples of human GIST cases and to verify their characteristics in vitro or in vivo. Tumor tissues were collected and immediately processed for culture and transplantation into NOG mice. Two cell lines, GK1C and GK3C, together with three xenografts, GK1X, GK2X and GK3X, were generated successfully. The established 
Table I. Patient characteristics.

Clinical sample, $\mathrm{N}=18(\%)$

\begin{tabular}{lc}
\hline Age (years), mean (range) & $61(43-75)$ \\
$\leq 69$ & $16(77.8)$ \\
$>70$ & $5(22.2)$ \\
Gender & \\
Male & $10(44.4)$ \\
Female & $11(55.6)$ \\
Tumor size $(\mathrm{cm})$ & \\
$\leq 5$ & $10(55.6)$ \\
$>5^{\mathrm{a}}$ & $8(44.4)$ \\
Mitotic index $(/ 50 \mathrm{HPF})$ & \\
$\leq 5$ & $12(66.7)$ \\
$>5^{\mathrm{a}}$ & $6(33.3)$ \\
Risk of metastasis & \\
Very low & $2(11.1)$ \\
Low & $7(27.8)$ \\
Intermediate & $4(22.2)$ \\
High & $8(38.9)$ \\
Immunohistochemistry & \\
KIT & $18(100)$ \\
CD34 & $18(100)$ \\
\hline
\end{tabular}

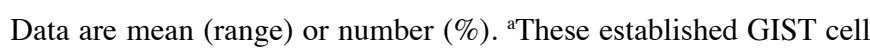
lines and xenografts were classified as high risk. ${ }^{b}$ Fletcher's risk classification.

GIST cell lines and xenografts were characterized using cell morphology, growth kinetics, immunohistochemistry, drug sensitivity and tumorigenicity in SCID or nude mice. This new GIST model may be helpful in improving our understanding of the molecular mechanisms of $c$-KIT- or PDGFRA-mediated metastasis and may be useful for assessments of molecular therapeutics, drug resistance and in vivo imaging.

\section{Materials and methods}

Clinical samples. This study was approved by the Ethics Committee of the Chamber of Surgeons of the School of Medicine, Keio University (no. 17-47). Human gastrointestinal stromal tumors (GISTs) were obtained from patients undergoing surgical resection following informed patient consent. Between November, 2007 and June, 2010, GIST tissues from 18 patients were collected and cultured or implanted into NOG mice. In addition to histological criteria, the following antibodies were used for immumohistological classification of all GISTs: CD117, CD34 and Ki-67. The mitotic count was categorized as follows: $<5 / 50$ high power fields (HPF), 5-10/50 HPF, or $>10 / 50 \mathrm{HPF}$ according to the GIST consensus approach of Fletcher risk classification (21). Metastatic risk was classified as low, intermediate, or high, respectively, by Miettinen classification. Patient data including gender, age, tumor size, clinicopathological and histopathological results were obtained from the clinical and pathological records. Table I documents the profile of samples from patients with GISTs in the present study.

Primary culture and evaluation of tumor forming ability. Clinical samples were subjected to mechanical and enzymatic dissociation. The cells were cultured in RPMI-1640 containing $20 \%$ fetal bovine serum (FBS; Invitrogen, Carlsbad, CA, USA), penicillin-streptomycin mixed solution (penicillin 10,000 units/ml, streptomycin 10,000 $\mu \mathrm{g} / \mathrm{ml}$; Nacalai Tesque Inc., Kyoto, Japan) and $10 \mathrm{ng} / \mathrm{ml}$ SCF (Peprotech Inc., Rocky Hill, NJ, USA). In all experiments, cells were cultured at $37^{\circ} \mathrm{C}$ in a humidified $5 \% \mathrm{CO}_{2}, 95 \%$ air atmosphere. After culture, the established GIST cells were collected and re-suspended in HBSS. Cell suspensions were then mixed with Matrigel (1:1) (Becton-Dickinson, San Jose, CA, USA). The cell-Matrigel suspension was then subcutaneously injected into SCID (C.B-17/lcr-scid/scidJcl) mice, aged 8 to 10 weeks (Japan Clea Laboratories, Tokyo, Japan) under anesthesia. Tumor growth was observed weekly after inoculation. Pieces of subcutaneous tumors were re-transplanted and embedded in paraffin.

Implantation of tumor tissues. Tumor tissues from GIST patients were implanted into NOG (NOD/Shi-scid, IL-2Rrnu) mice. These tumor tissues were obtained from surgical resection of the primary tumor. Tumor tissues were collected in serum-free Hanks' balanced salt solution (HBSS) medium and immediately processed for transplantation. The tumor specimens were cut into small fragments $\left(5 \mathrm{~mm}^{3}\right)$ and kept in a Petri dish containing physiological saline. The tissue fragments were implanted bilaterally into 6-week old NOG mice. Tumor growth was monitored until it reached $1 \mathrm{~cm}$ in diameter after three months. These xenograft lines were maintained by serial passage in NOG mice in our animal facility. GIST engraftment was assessed by immunohistochemistry and DNA mutation assay.

Immunohistochemical staining. Specimens were fixed with $4 \%$ paraformaldehyde for $24 \mathrm{~h}$ at room temperature. Immunohistochemical staining for CD117 (KIT) was performed on 4- $\mu \mathrm{m}$ sections placed on pre-coated slides with APS (Matsunami Glass Industries Ltd., Osaka, Japan). Briefly, slides were incubated with blocking reagent-N101 (Wako Pure Chemicals Industries, Ltd., Tokyo, Japan) for $20 \mathrm{~min}$. After rinsing in PBST, avidin and biotin blocking was performed for 15 min each. Slides were incubated with anti-human CD117 mAb (Dako). A biotinylated antibody (Vectastain ABC kit) was then used as the secondary antibody for $30 \mathrm{~min}$, with a 10-min DAB staining reaction. Slides were counterstained with haematoxylin. Finally slides were cover-slipped with aqueous mounting medium (Aquatex ${ }^{\circledR}$, Merck). Specimens were analyzed under a light microscope, and CD117 positivity was defined as strong membrane and cytoplasmic staining in at least $50-75 \%$ of cells.

Flow cytometric analysis. For the evaluation of CD117 (KIT) and PDGFRA (CD140a) phosphorylation status, cells were collected and washed with PBS and fixed with $2 \%$ paraformaldehyde (PFA) at $37^{\circ} \mathrm{C}$ in a water bath for $10 \mathrm{~min}$. The cells were then washed with PBS and pelleted by centrifugation 
Table II. Analysis of c-KIT and PDGFRA mutations.

\begin{tabular}{lcccc}
\hline ID & Cell line & Xenograft & $c$-KIT mutation & PDGFRA mutation \\
\hline GIST 1 & GK1C & GK1X & Ex.11: del (550-558) & WT \\
GIST 2 & - & GK2X & Ex.11: del (557-558) & WT \\
GIST 3 & GK3C & GK3X & Ex.11: del (591-592) & WT \\
\hline
\end{tabular}

DNA sequencing results of $c$-KIT exons 9,11,13 and 17 and PDGFRA exons 12 and 18. Miettinen classification (23). Image obtained by using the SeqScape v2.6 sequence analysis program. WT, wild-type.

(800 $\mathrm{x} \mathrm{g}$ ) for $5 \mathrm{~min}$, and the supernatant was removed. The tube was mixed to disrupt the pellet and permeabilized by adding $500 \mu \mathrm{l}$ of $90 \%$ methanol (for $1 \times 10^{6}$ cells) and incubating on ice for $15 \mathrm{~min}$. After blocking on ice for $10 \mathrm{~min}$, cells were then washed by PBS and incubated with primary antibodies against phospho-KIT (Tyr719) and phospho-PDGFRA (Tyr754) (Cell Signaling Technology, Inc., Danvers, MA, USA) for $60 \mathrm{~min}$ at room temperature. The cells were washed with PBS before incubation for 30 min with Alexa Fluor 488 donkey antirabbit IgG antibody (Invitrogen, Carlsbad, CA, USA). Each sample was then analyzed using a FACSCalibur ${ }^{\mathrm{TM}}$ (BectonDickinson, Franklin Lakes, NJ, USA). The distribution of cells was analyzed using FlowJo software (Tomy Digital Biology, Tokyo, Japan).

Assessment of imatinib sensitivity of the cell lines. Cells were plated in 96-well microplates and cultured for $12 \mathrm{~h}$ before exposure to imatinib (1-100 $\mu \mathrm{M})$ for $72 \mathrm{~h}$. The cells were quantified by the WST- 8 assay. The optical density (OD) was determined with Sunrise Rainbow (Wako Pure Chemical Industries). The rate of inhibition was calculated as follows: $\%$ of inhibition = (OD of treated group - blank)/(OD of control group - blank) $\mathrm{x} 100 \%$. The concentration of tested drugs resulting in $50 \%$ growth inhibition $\left(\mathrm{IC}_{50}\right)$ was calculated.

In vivo drug assay. Tumor tissue was collected in serum-free HBSS medium and immediately processed for transplantation. The tumor specimen was cut into small fragments $2 \mathrm{~mm}^{3}$ and kept in a Petri dish containing physiological saline. The tissue fragments were implanted bilaterally into 7-week-old nude mice $(n=10)$. Growth factors, hormones, Matrigel and other supplements were not used. Drug administration was initiated when tumors in each group achieved an average volume of $120-350 \mathrm{~mm}^{3}$. Mice were randomly allocated to control and treatment groups. Treatment groups consisted of control and imatinib. Each treatment group included 6-8 mice. Imatinib was administered at a dose of $40 \mathrm{mg} / \mathrm{kg} / \mathrm{day}$ and given by oral gavage daily for 28 days. Control animals received saline administration. Tumor volume (TV) was determined from caliper measurements of tumor length (L) and width (W) according to the formula $\mathrm{LW}^{2} / 2$. TV and body weight were determined every two to three days and on the day of evaluation. Relative TV (RTV) on evaluation day was calculated as the ratio of $\mathrm{TV}$ on evaluation day to that on day 1 according to the following formula: RTV $=$ (TV on evaluation day $) /(\mathrm{TV}$ on day 1). The percentage of tumor growth inhibition (TGI \%) was calculated as follows: TGI $(\%)=[1$ - (tumor volume of treatment group on evaluation day - tumor volume of treatment group on day 1)/(tumor volume of control group at evaluation day - tumor volume of control group on day 1)] x $100 \%$. The percentage of body weight change (BWC\%) was calculated as follows: $\mathrm{BWC}(\%)=[(\mathrm{BW}$ on evaluation day $)-(\mathrm{BW}$ on day 1$)] /$ (BW on day 1 ) x $100 \%$.

Mutation analysis. DNA was extracted from gastric cancer cell lines using a QIAmp DNA Mini kit (Qiagen, Düsseldorf, Germany). A NanoDrop ND-1000 (NanoDrop Technologies) was used to evaluate the concentration of the samples. c-KIT gene exons 9, 11, 13 and 17 and PDGFRA gene exons 12 and 18 were amplified in PCR reactions. DNA sequencing was performed by SRL, Inc. Images were obtained with the SeqScape v2.6 sequence analysis program.

Statistical analysis. Data values are expressed as means \pm SD or mean-fold change. The statistical significances of mean values were determined by one-way ANOVA first, then by Studen't t-test. P-value $\leq 0.05$ was considered significant for the ANOVA test. P-value $\leq 0.01$ was considered significant for the Student's t-test.

\section{Results}

Establishment of GIST cell lines and xenografts from clinical samples. To establish cell lines and xenografts from GIST tumors, tumor tissue was subcutaneously transplanted to NOG mice or put into primary culture. GIST cell lines and xenografts were established from three clinical specimens (GIST1, GIST2 and GIST3). These specimens were positive for KIT and CD34, which were classified as high risk GISTs based on tumor size and mitotic rate. Mutation analyses of c-KIT exons 9, 11, 13, 14 and 17 and PDGFRA exons 12 and 18 were performed by direct sequencing. Mutations were detected in c-KIT exon 11: del (550-558), del (557-558) and del (591-592), respectively, but a PDGFRA mutation was not detected (Table II). The two new cell lines (GK1C and GK3C) and three xenografts (GK1X, GK2X and GK3X) were generated from these clinical samples (Fig. 1A and B and Fig. 2A-C). The established cells and xenografts were subject to repeated passages. In xenografts, tumor-doubling time was found to be $\sim 45$ days. Microscopic examination of the initial human GISTs and the xenografts revealed similar morphological appearances (Fig. 2D-F and J-L), comprising moderate cellular tissue with atypical epithelioid and spindleshaped cells. Immunohistochemical or immunocytochemical 


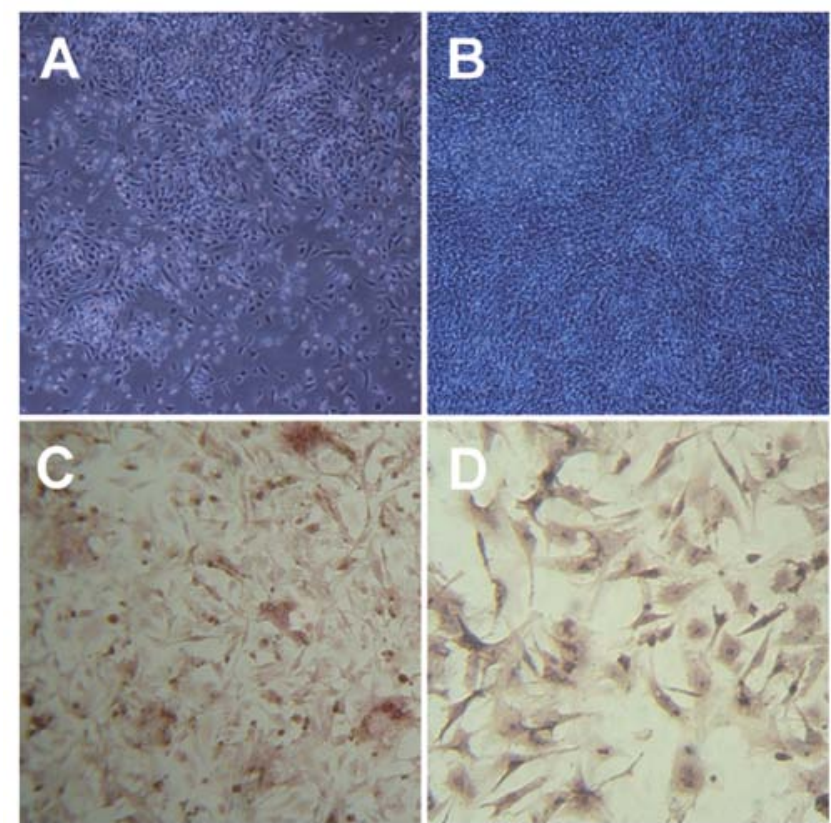

Figure 1. Histological findings of gastrointestinal stromal tumor (GIST) cell lines derived from samples of patients with GIST. Newly established GIST cell lines, (A) GK1C and (B) GK3C (phase contrast, magnification, $\mathrm{x} 200$ ). Immunohistochemical analysis of KIT expression in (C) GK1C and (D) GK3C as determined by staining with DAB (magnification, $\mathrm{x} 200-400$ ). analysis for KIT expression in the 2 cell lines and 3 xenografts was carried out by DAB staining. These results indicated that established cells and xenografts were positive for KIT (Fig. 1C and D and Fig. 2G-I and M-O).

Potential of GIST cell lines for tumorigenesis. Cells $\left(5 \times 10^{6}\right)$ from 2 GIST cell lines (GK1C and GK3C) were injected subcutaneously into SCID mice. Tumor formation was observed for 12 weeks after injection (Fig. 3A and B). KIT expression was detected by immunohistochemistry (Fig. 3C and D). These results indicated that the 2 GIST cell lines possessed the ability for tumorigenesis.

Intracellular phosphorylation of KIT and PDGFRA. To investigate the activation of KIT and PDGFRA, we examined the phosphorylation of the signaling pathway. GK1C and GK3C cells were treated with anti-phospho-KIT or anti-phosphoPDGFRA antibody. The degree of phosphorylation was measured by flow cytometric analysis and expressed as mean fluorescence intensity (MFI). Phosphorylation of KIT and PDGFRA was detected in both cell lines. MFI values for phosphorylation of KIT and PDGFRA in GK1C were 8.40 \pm 0.12 and $3.81 \pm 0.18$, respectively. In GK3C, MFI values were $6.71 \pm 1.38$ and $4.05 \pm 0.05$ (Fig. 3E). In both GIST cell lines, enhanced phosphorylation of KIT was marked when compared
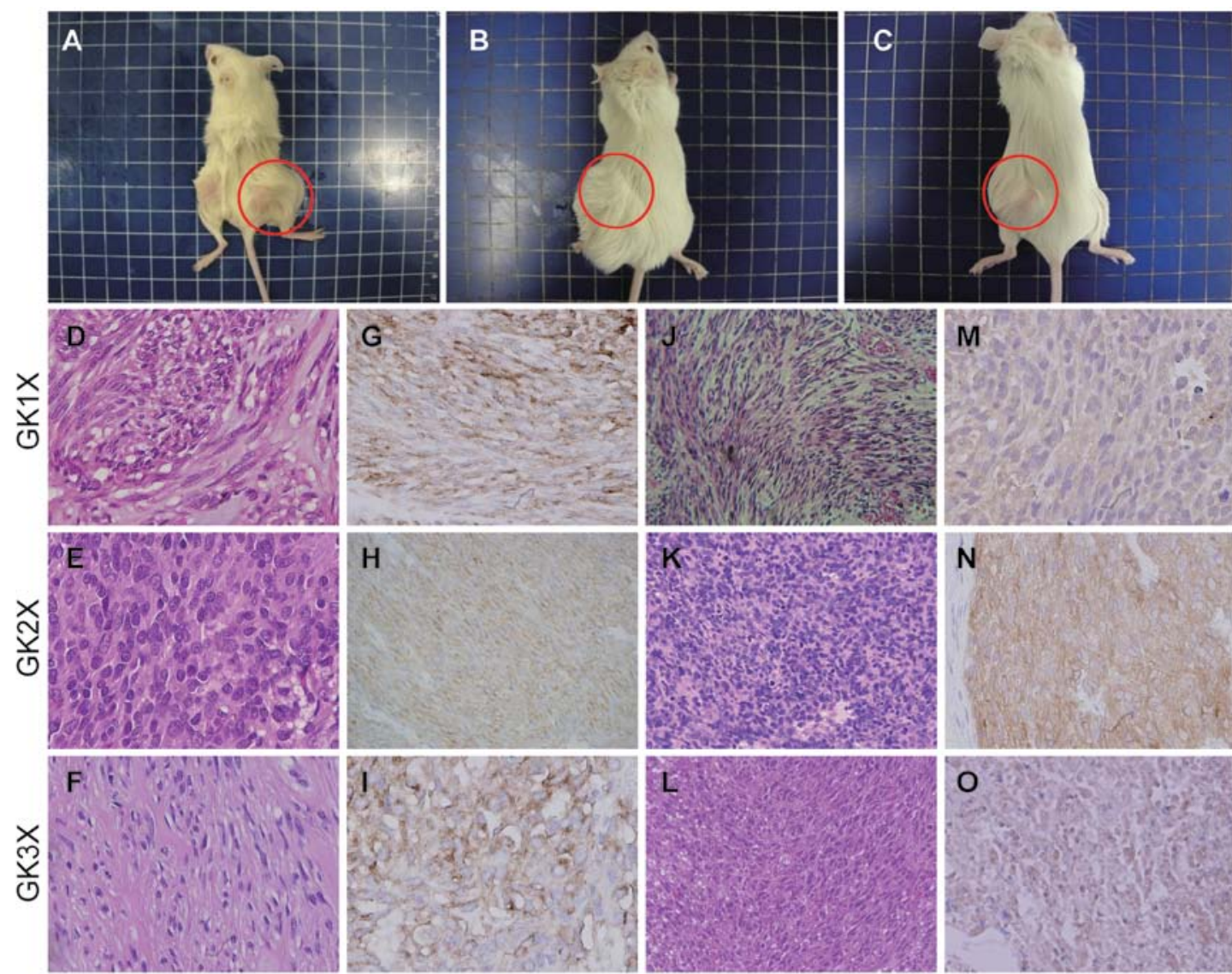

Clinical Specimen

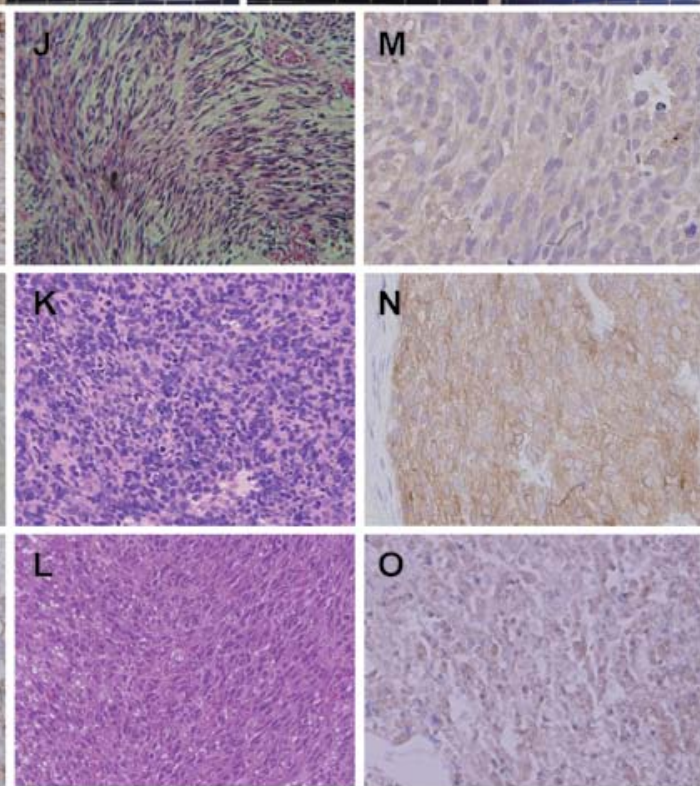

Xenograft Line

Figure 2. Macroscopic and microscopic findings of GIST xenografts in SCID mice. SCID mice displaying xenografts on their backs: (A) GK1X, (B) GK2X and (C) GK3X). (D-I) H\&E staining and immunohistological staining for KIT in the initial human GISTs and (J-O) GIST xenograft lines established from the clinical samples. (Magnification, x100-200). 

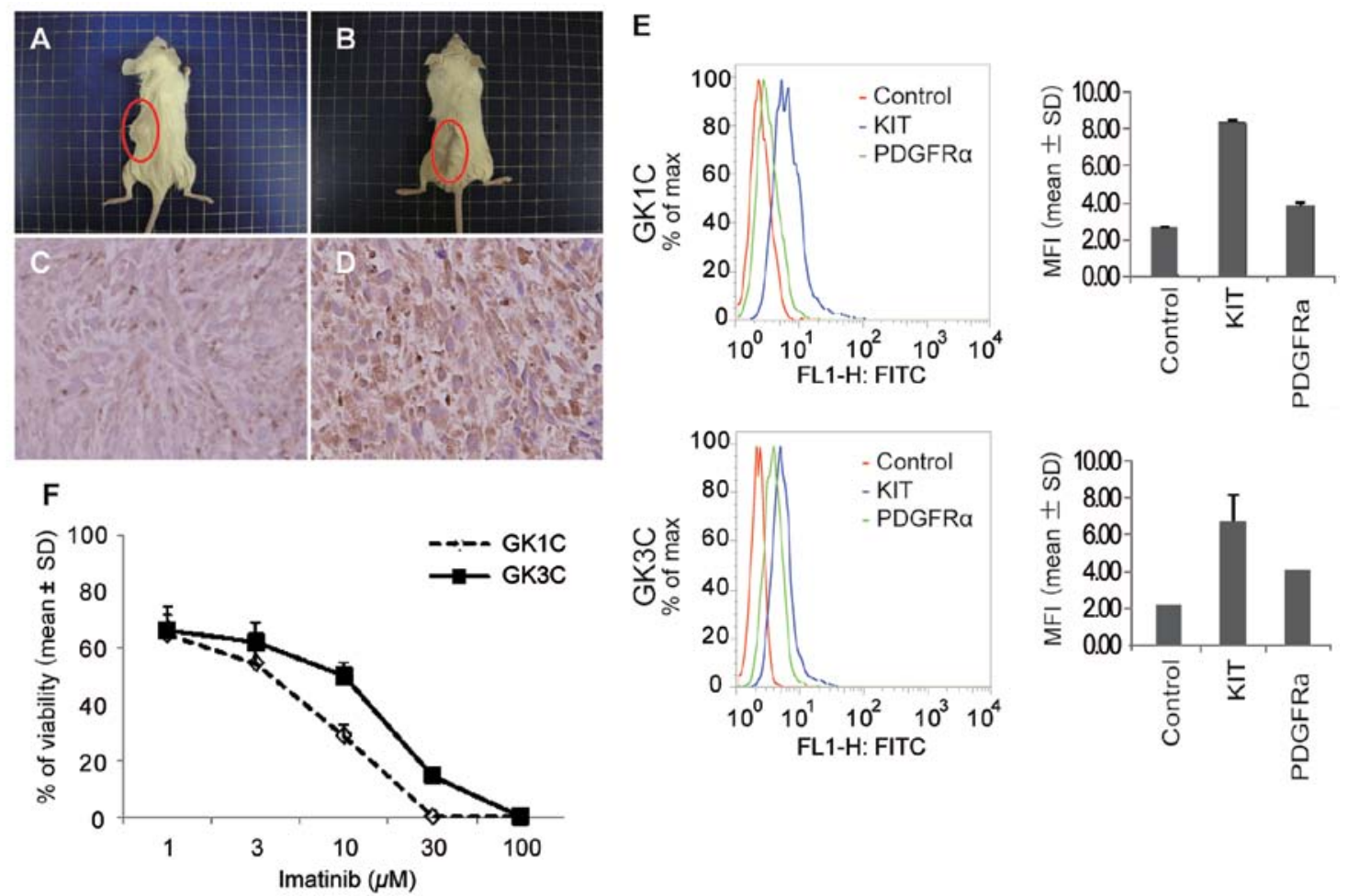

Figure 3. Characterization and drug sensitivity of established GIST cell lines. GIST cell lines were prepared by injecting $5 \times 10^{6}$ cells subcutaneously into SCID mice: (A) GK1C and (B) GK3C. Tumor formation was observed for 3 or 6 months after cell injection. In tumors derived from the GIST cell lines, KIT expression was detected by immunohistochemistry: (C) GK1C and (D) GK3C. (E) Status of phosphorylation of KIT and PDGFRA was detected by flow cytometry and expressed as the mean of fluorescence intensity (MFI). (F) GIST cell lines showed sensitivity to imatinib with $\mathrm{IC}_{50}$ values of $3.71 \mathrm{or} 11.0 \mu \mathrm{M}$. Data are the means \pm SD from 3 independent experiments.
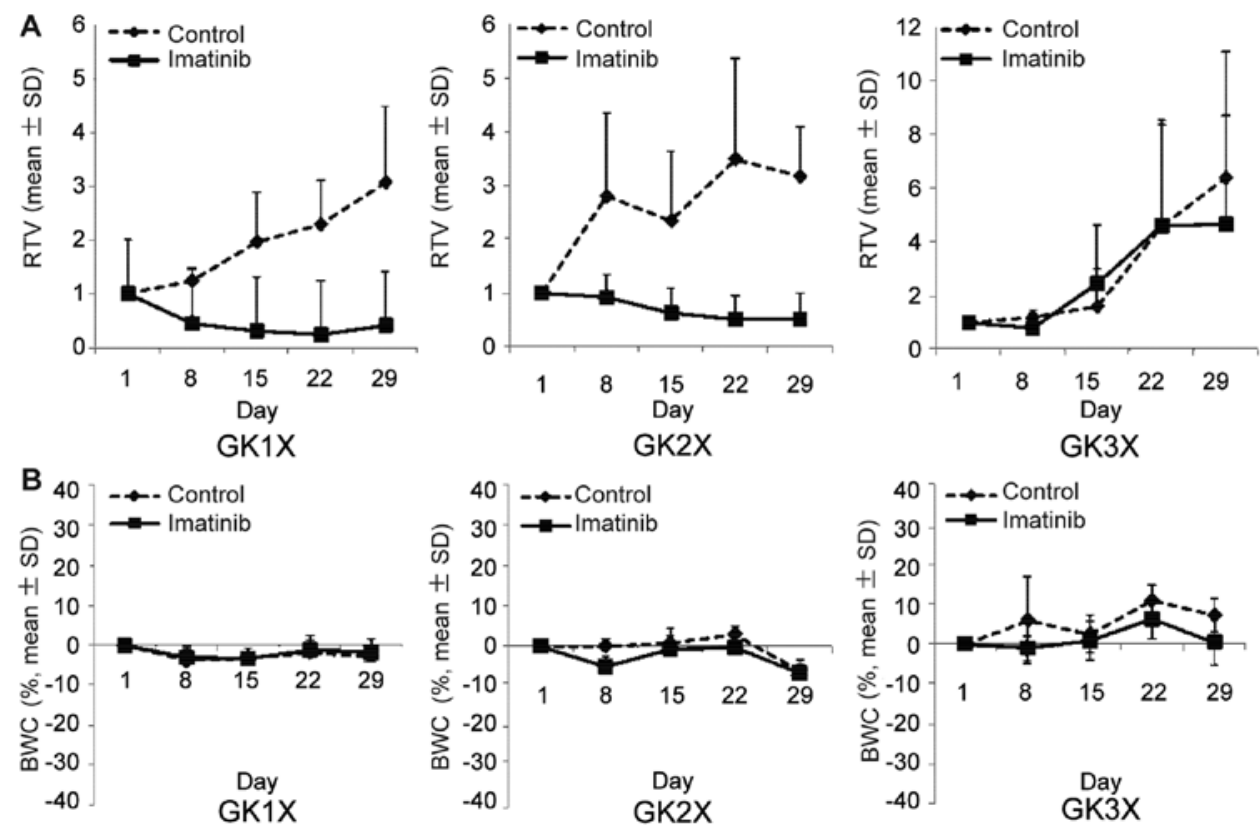

Figure 4. Effect of imatinib on the growth of GIST xenografts. Tumor tissue fragments $\left(2 \mathrm{~mm}^{3}\right)$ were transplanted s.c. in the backs of SCID mice that were randomized to 4 groups $(\mathrm{n}=6-8)$. Doses of $40 \mathrm{mg} / \mathrm{kg} / \mathrm{day}$ of imatinib or saline (control) were administered by oral gavage daily for 28 days. Tumor size and body weight were measured every three days. (A) Relative tumor volume (RTV) on the day of evaluation was calculated as the ratio of TV on evaluation day to that on day 1. (B) The percentage of body weight change (BWC\%) was calculated as follows: BWC $(\%)=[(\mathrm{BW}$ on evaluation day) $-(\mathrm{BW}$ on day 1$)] /(\mathrm{BW}$ on day 1) x $100 \%$.

to that of PDGFRA. These data were consistent with the cell lines having function-specific proliferation properties of GIST.
In vivo imatinib sensitivity. The effects of imatinib on the growth of GK1C and GK3C cells were evaluated. Cells were 
seeded and incubated for $12 \mathrm{~h}$ before treatment, and then exposed to imatinib $(0-100 \mu \mathrm{M})$ for $72 \mathrm{~h}$. The percentage of cellular growth was assessed using WST-8. GK1C and GK3C cells showed sensitivity to imatinib in vitro with $\mathrm{IC}_{50}$ values of 4.6 \pm 0.96 and $11.0 \pm 0.17 \mu \mathrm{M}$, respectively (Fig. 3F).

Effect of imatinib on GIST xenograft models. The antitumor activity of imatinib was examined in the human GIST xenograft model. Mice with tumors derived from GK1X, GK2X and GK3X were divided into groups for treatment with saline (control) or imatinib for 28 days. Tumor volume (TV) was evaluated between groups every three days. Fig. 4A shows the change in TV in each group. The average RTV on the day of sacrifice for imatinib was $1.86 \pm 2.42$, whereas for controls it was $4.21 \pm 1.88(\mathrm{P}<0.05)$. Additionally, the percentage of tumor growth inhibition for imatinib was $86.7 \%$ in GK1X, $84.0 \%$ in GK2X and $27.1 \%$ in GK3X. The treatment was well tolerated by the mice, with no signs of toxicity or weight loss during therapy (Fig. 4B). These results indicated that imatinib inhibited the growth of tumors formed by xenografts compared to the control.

\section{Discussion}

Gastrointestinal stromal tumors (GISTs) are one of the most common mesenchymal tumors of the gastrointestinal tract (1-3\% of all gastrointestinal malignancies). Until 10 years ago, these tumors were widely considered variants of smooth muscle tumors: leiomyomas if benign and leiomyosarcomas if malignant. The term gastrointestinal autonomic nerve tumor (GANT) also refers to GIST, based on identical histologic and immunohistochemical features and c-KIT mutations (22). The incidence of GIST has been estimated to be 14-20 cases per million, but minimal incidental GISTs are far more common. Most GISTs occur on a sporadic basis, but some occur in clinical syndromes. The most common of these is neurofibromatosis 1, in which GISTs usually occur in the small intestine, often as multiple, clinically indolent tumors. Familial GISTs are based on hereditary c-KIT/PDGFRA-activating mutations, and pediatric GISTs are linked to loss of succinate dehydrogenase subunit B (SDHB) and Carney triad and Carney-Stratakis syndromes (CSS), the latter being an autosomal dominant tumor syndrome combining GIST and paraganglioma (23).

Two new human GIST cell lines (GK1C and GK3C) and three xenografts (GK1X, GK2X and GK3X) were established from surgical tissue samples and characterized. In previous studies, to improve the cure rate of GIST, researchers have attempted to establish GIST cell lines and xenografts for basic and clinical study. However, the success rate of establishing cell lines and xenografts is very low. There have been reports that several GIST cell lines and tumors have been generated from clinical specimens or mice. GIST-T1 was established from a metastatic plural tumor from a GIST of the stomach in a Japanese woman, and was characterized by immunohistochemistry, conventional banding methods, comparative genomic hybridization (CGH), and fluorescence in situ hybridization (FISH). Immunohistochemically, the cells were strongly positive for CD34 and c-KIT, but not for desmin, S-100 protein, or $\alpha$-smooth muscle actin (24). GIST cell line GIST882 expresses an activating $c$-KIT mutation (K642E) in the first part of the cytoplasmic split tyrosine kinase domain. Notably, the K642E substitution is encoded by a homozygous exon 13 missense mutation, and, therefore, GIST882 cells do not express native KIT. GIST882 KIT protein is constitutively tyrosine phosphorylated, but tyrosine phosphorylation was abolished after incubating the cells with the selective tyrosine kinase inhibitor imatinib (25). GIST-H1 was established and passaged more than 60 times over a year. The population doubling time calculated in log phase of growth was $47.5 \mathrm{~h}$. The cloning efficiency in soft agar averaged $24.8 \%$. From electron microscopic evaluation, the cytoplasm was rich in ribosomes and mitochondria. Immunohistochemical analysis revealed aneuploidy with modal chromosomal numbers ranging from 60 to 98 . The GIST cells transplanted in nude mice were tumorigenic (26). A culture model of GIST-DR derived from GIST induced by duodenal reflux was established. GIST-DR cells, both in vitro and in vivo, were immunopositive for both KIT and CD34 and imatinib blocked the proliferation of this cell line (27). Although GIST-T1 and GIST882, GIST-H1 and GIST-DR (induced by chemical carcinogenesis), have been established, long-term maintenance in vitro and in vivo might be difficult.

Our established cell lines and xenografts were capable of repeated passage for long periods, making them available for the study of GIST. To investigate their phenotype, immunohistochemical and cytochemical analyses of KIT expression of the established cell lines (GK1C and GK3C) and xenografts (GK1X, GK2X and GK3X) were undertaken. These results showed that the cell lines and xenografts were positive for KIT. In addition, the increased phosphorylation of KIT and PDGFRA was detected in both cell lines, GK1C and GK3C. In both, the intensity enhancement of phosphorylation of KIT was 2.2- to 4.8-fold higher than that of PDGFRA.

The discovery of gain-of-function mutations in the $c$-KIT proto-oncogene in GIST by Hirota and colleagues (28) in 1998 was crucial to our present understanding of the genesis and classification of these tumors. Sommer et al (29) reported that constitutive KIT signaling is both critical and sufficient for induction of GIST and hyperplasia of ICC (interstitial cells of Cajal). In addition, GIST is known to represent a discrete neoplastic entity, possibly arising from a progenitor related to ICC $(30,31)$. Although, it is well accepted that KIT activity plays an important role in the tumorigenesis of GIST, little is known regarding the main cause of $c$-KIT mutation.

In patients, malignant GISTs often metastasize to the liver and disseminate within the peritoneal cavity. The tumorigenicity of GK1C and GK3C cell lines was examined using immune-deficient SCID mice, into which $5 \times 10^{6}$ GIST cells had been transplanted subcutaneously. Both GK1C and GK3C formed tumors ectopically. Moreover, the tumors were KIT-positive by immunohistochemical analysis. Recent advances in molecular biology have highlighted the complicated tumorigenic mechanism of various tumors. The tumorigenicity of GISTs has been explained by activating mutations of the $c-K I T$ or PDGFRA gene (32). Thus, these data indicate that $\mathrm{GK} 1 \mathrm{C}$ and $\mathrm{GK} 3 \mathrm{C}$ have the properties of tumorigenic GISTs.

Imatinib inhibits KIT tyrosine kinase activity, enabling pharmacologic attack on a specific molecular target in GIST. Early clinical trials with imatinib have resulted in marked 
remission of metastatic GIST, a type of tumor that has previously proven resistant to all other forms of chemotherapy. Imatinib has also proven highly active in patients with unresectable GISTs expressing immunohistochemically detectable c-KIT protein $(33,34)$. A recent report showed that all KIT mutant isoforms, but only a subset of platelet-derived growth factor receptor $\alpha$ (PDGFRA) mutant isoforms, were sensitive to imatinib in vitro (35). In this study, imatinib blocked the proliferation of cell lines (GK1C and GK3C) and xenografts (GK1X, GK2X and GK3X). These results indicate that the newly established cell lines and xenografts are useful as models of imatinib-sensitive GIST.

Within 12 to 36 months, $50-70 \%$ of patients with GISTs will progress following imatinib therapy $(36,37)$. The most common cause of secondary resistance $(50-80 \%)$ is a second mutation involving the same allele as the initial mutation, a phenomenon that has not been documented in tumors with primary resistance $(14,38)$. However, there must be $c-K I T-$ negative GISTs and the main cause of the c-KIT mutation has not been fully examined. On the other hand, it has been reported that imatinib is a substrate for P-glycoprotein, a multi-drug resistance (MDR) protein, typically involved in antitumor drug transport (39), and breast cancer resistance protein (BCRP), a protein implicated in drug transport in the gut epithelium (40). Increased expression of these proteins results in decreased drug levels. The mechanisms underlying the remaining secondary resistance have not yet been clarified. Our novel GIST cell lines (GK1C and GK3C) are easy to transplant into SCID mice, and represent a useful model for testing chemotherapeutic agents in vivo.

In conclusion, our novel models for GIST are important research tools for investigating relevant cellular alterations that may be pertinent to the human disease state. In addition, such models may be beneficial for pre-clinical testing of new therapeutic strategies.

\section{References}

1. Nowain A, Bhakta H, Pais S, Kanel G and Verma S: Gastrointestinal stromal tumors: clinical profile, pathogenesis, treatment strategies and prognosis. J Gastroenterol Hepatol 20: 818-824, 2005.

2. Heinrich MC, Rubin BP, Longley BJ, et al: Biology and genetic aspects of gastrointestinal stromal tumors: KIT activation and cytogenetic alterations. Hum Pathol 33: 484-495, 2002.

3. Vlahovic $\mathrm{G}$ and Crawford J: Activation of tyrosine kinases in cancer. Oncologist 8: 531-538, 2003.

4. Eisenberg BL and Judson I: Surgery and imatinib in the management of GIST: emerging approaches to adjuvant and neoadjuvant therapy. Ann Surg Oncol 11: 465-475, 2004.

5. Heinrich MC and Corless CL: Gastric GI stromal tumors (GISTs): the role of surgery in the era of targeted therapy. J Surg Oncol 90: 195-207, 2005.

6. Samiian L, Weaver M and Velanovich V: Evaluation of gastrointestinal stromal tumors for recurrence rates and patterns of long-term follow-up. Am Surg 70: 187-191, 2004.

7. DeMatteo RP, Heinrich MC, El-Rifai WM and Demetri G: Clinical management of gastrointestinal stromal tumors: before and after STI-571. Hum Pathol 33: 466-477, 2002.

8. Demetri GD, vonMehren M, Blanke CD, Vanden Abbeele AD, Eisenberg B, Roberts PJ, et al: Efficacy and safety of imatinib mesylate in advanced gastrointestinal stromal tumors. N Engl J Med 347: 472-480, 2002.

9. Bauer S, Duensing A, Demetri GD and Fletcher JA: KIT oncogenic signaling mechanisms in imatinib-resistant gastrointestinal stromal tumor: PI3-kinase/AKT is a crucial survival pathway. Oncogene 26: 7560-7568, 2007.
10. Sleijfer S, Wiemer E, Seynaeve C and Verweij J: Improved insight into resistance mechanisms to imatinib in gastrointestinal stromal tumors: a basis for novel approaches and individualization of treatment. Oncologist 12: 719-726, 2007.

11. Wardelmann E, Buttner R, Merkelbach-Bruse $\mathrm{S}$ and Schildhaus HU: Mutation analysis of gastrointestinal stromal tumors: increasing significance for risk assessment and effective targeted therapy. Virchows Arch 451: 743-749, 2007.

12. Tornillo L and Terracciano LM: An update on molecular genetics of gastrointestinal stromal tumours. J Clin Pathol 59: 557-563, 2006.

13. Sleijfer S, Wiemer E and Verweij J: Drug insight: gastrointestinal stromal tumors (GIST) - the solid tumor model for cancerspecific treatment. Nat Clin Pract Oncol 5: 102-111, 2008.

14. Antonescu CR, Besmer P, Guo T, Arkun K, Hom G, Koryotowski B, et al: Acquired resistance to imatinib in gastrointestinal stromal tumor occurs through secondary gene mutation. Clin Cancer Res 11: 4182-4190, 2005.

15. Debiec-Rychter M, Dumez H, Judson I, Wasag B, Verweij J, Brown M, Dimitrijevic S, Sciot R, Stul M, Vranck H, Scurr M, Hagemeijer A, van Glabbeke M and van Oosterom AT; EORTC Soft Tissue and Bone Sarcoma Group: Use of c-KIT/PDGFRA mutational analysis to predict the clinical response to imatinib in patients with advanced gastrointestinal stromal tumours entered on phase I and II studies of the EORTC Soft Tissue and Bone Sarcoma Group. Eur J Cancer 40: 689-695, 2004.

16. Heinrich MC, Corless CL, Blanke CD, Demetri GD, Joensuu H, Roberts PJ, et al: Molecular correlates of imatinib resistance in gastrointestinal stromal tumors. J Clin Oncol 24: 4764-4774, 2006.

17. Mahadevan D, Cooke L, Riley C, Swart R, Simons B, Della Croce K, Wisner L, Iorio M, Shakalya K, Garewal H, Nagle R and Bearss D: A novel tyrosine kinase switch is a mechanism of imatinib resistance in gastrointestinal stromal tumors. Oncogene 26: 3909-3919, 2007.

18. Thao le B, Vu HA, Yasuda K, Taniguchi S, Yagasaki F, Taguchi T, Watanabe $\mathrm{T}$ and Sato Y: Cas-L was overexpressed in imatinibresistant gastrointestinal stromal tumor cells. Cancer Biol Ther 8: 683-688, 2009.

19. Steigen SE and Eide TJ: Trends in incidence and survival of mesenchymal neoplasm of the digestive tract within a defined population of northern Norway. APMIS 114: 192-200, 2006.

20. Trent JC and Benjamin RS: New developments in gastrointestinal stromal tumor. Curr Opin Oncol 18: 386-395, 2006.

21. Fletcher CD, Berman JJ, Corless C, Gorstein F, Lasota J, Longley BJ, Miettinen M, O'Leary TJ, Remotti H, Rubin BP, Shmookler B, Sobin LH and Weiss SW: Diagnosis of gastrointestinal stromal tumors: a consensus approach. Int J Surg Pathol 10: 81-89, 2002.

22. Lee JR, Joshi V, Griffin JW Jr, et al: Gastrointestinal autonomic nerve tumor: immunohistochemical and molecular identity with gastrointestinal stromal tumor. Am J Surg Pathol 25: 979-987, 2001.

23. Miettinen M and Lasota J: Gastrointestinal stromal tumors: review on morphology, molecular pathology, prognosis, and differential diagnosis. Arch Pathol Lab Med 130: 1466-1478, 2006.

24. Taguchi T, Sonobe H, Toyonaga S, Yamasaki I, Shuin T, Takano A, Araki K, Akimaru K and Yuri K: Conventional and molecular cytogenetic characterization of a new human cell line, GIST-T1, established from gastrointestinal stromal tumor. Lab Invest 82: 663-665, 2002.

25. Tuveson DA, Willis NA, Jacks T, Griffin JD, Singer S, Fletcher CD, Fletcher JA and Demetri GD: STI571 inactivation of the gastrointestinal stromal tumor c-KIT oncoprotein: biological and clinical implications. Oncogene 20: 5054-5058, 2001.

26. Zhu B, Liao G, Liu S, Huang B, Wu S, Zhou J, Gu H and Zhu H: Characteristics and establishment of cell lines from human gastrointestinal stromal tumors. Zhong Nan Da Xue Xue Bao Yi Xue Ban 35: 1138-1144, 2010

27. Mukaisho K, Miwa K, Totsuka Y, Shimomura A, Sugihara H, Wakabayashi K and Hattori T: Induction of gastric GIST in rat and establishment of GIST cell line. Cancer Lett 231: 295-303, 2006.

28. Hirota S, Isozaki K, Moriyama Y, Hashimoto K, Nishida T, Ishiguro S, Kawano K, Hanada M, Kurata A, Takeda M, Muhammad TG, Matsuzawa Y, Kanakura Y, Shinomura Y and Kitamura Y: Gain-of-function mutations of c-kit in human stromal tumors. Science 279: 577-580, 1998. 
29. Sommer G, Agosti V, Ehlers I, Rossi F, Corbacioglu S, Farkas J, Moore M, Manova K, Antonescu CR and Besmer P: Gastrointestinal stromal tumors in a mouse model by targeted mutation of the kit receptor tyrosine kinase. Proc Natl Acad Sci USA 100: 6706-6711, 2003.

30. Kindblom LG, Remotti HE, Aldenborg F and Meis-Kindblom JM: Gastrointestinal pacemaker cell tumor (GIPACT): gastrointestinal stromal tumors show phenotypic characteristics of the interstitial cells of Cajal. Am J Pathol 152: 1259-1269, 1998.

31. Sircar K, Hewlett BR, Huizinga JD, Chorneyko K, Berezin I and Riddell RH: Interstitial cells of Cajal as precursors of gastrointestinal stromal tumors. Am J Surg Pathol 23: 377-389, 1999.

32. Heinrich MC, Corless CL, Duensing A, McGreevey L, Chen CJ Joseph N, et al: PDGFRA activating mutations in gastrointestinal stromal tumors. Science 299: 708-710, 2003.

33. Joensuu H, Roberts PJ, Sarlomo-Rikala M, Andersson LC, Tervahartiala P, Tuveson D, Silberman S, Capdeville R, Dimitrijevic S, Druker B and Demetri GD: Effect of the tyrosine kinase inhibitor STI571 in a patient with a metastatic gastrointestinal stromal tumor. N Engl J Med 344: 1052-1056, 2001.

34. van Oosterom AT, Judson I, Verweij J, Stroobants S, Donato di Paola E, Dimitrijevic S, Martens M, Webb A, Sciot R Van Glabbeke M, Silberman S and Nielsen OS: Safety and efficacy of imatinib (STI571) in metastatic gastrointestinal stromal tumours: a phase I study. Lancet 358: 1421-1423, 2001.

35. Heinrich MC, Corless CL, Demetri GD, Blanke CD, von Mehren M, Joensuu H, McGreevey LS, Chen CJ, Van den Abbeele AD, Druker BJ, Kiese B, Eisenberg B, Roberts PJ, Singer S, Fletcher CD, Silberman S, Dimitrijevic S and Fletcher JA: Kinase mutations and imatinib response in patients with metastatic gastrointestinal stromal tumor. J Clin Oncol 21: 4342-4349, 2003 .
36. Blanke CD, Rankin C, Demetri GD, Ryan CW, von Mehren M, Benjamin RS, Raymond AK, Bramwell VH, Baker LH, Maki RG, Tanaka M, et al: Phase III randomized, intergroup trial assessing imatinib mesylate at two dose levels in patients with unresectable or metastatic gastrointestinal stromal tumors expressing the kit receptor tyrosine kinase: S0033. J Clin Oncol 26: 626-632, 2008.

37. Verweij J, Casali PG, Zalcberg J, LeCesne A, Reichardt P, Blay JY, Issels R, van Oosterom A, Hogendoorn PC, Van Glabbeke M, Bertulli R, et al: Progression-free survival in gastrointestinal stromal tumours with high-dose imatinib: randomised trial. Lancet 364: 1127-1134, 2004.

38. Chen LL, Trent JC, Wu EF, Fuller GN, Ramdas L, Zhang W, Raymond AK, Prieto VG, Oyedeji CO, Hunt KK, Pollock RE, et al: A missense mutation in KIT kinase domain 1 correlates with imatinib resistance in gastrointestinal stromal tumors. Cancer Res 64: 5913-5919, 2004.

39. Theou N, Gil S, Devocelle A, Julie C, Lavergne-Slove A, Beauchet A, Callard P, Farinotti R, Le Cesne A, Lemoine A, Faivre-Bonhomme L, et al: Multidrug resistance proteins in gastrointestinal stromal tumors: site-dependent expression and initial response to imatinib. Clin Cancer Res 11: 7593-7598, 2005.

40. Burger H, Van Tol H, Boersma AW, Brok M, Wiemer EA, Stoter G and Nooter K: Imatinib mesylate (STI571) is a substrate for the breast cancer resistance protein (BCRP)/ABCG2 drug pump. Blood 104: 2940-2942, 2004. 